\title{
Assessment of Ocular Tear Film Stability in Subjects with High Total Cholesterol Levels
}

\author{
SAUD A. ALANAZI, Ph.D. \\ Cornea Research Chair, Department of Optometry, College of Applied Medical Sciences, King Saud University, \\ Riyadh, Saudi Arabia
}

\begin{abstract}
Background: High cholesterol levels are known to cause multiple complications and the correlations between dry eye disease and high cholesterol levels can be used as an indicator of the need for urgent treatment to prevent severe ocular complications.

Aim of Study: This study aimed to assess ocular tear film stability in subjects with high total cholesterol levels by using various dry eye diagnostic tests.

Subjects and Methods: Twenty male subjects aged 19-43 years ( $32.5 \pm 7.3$ years) with a high total cholesterol level $(6.2 \pm 0.7 \mathrm{mmol} / \mathrm{L})$ and an age-matched control group of twenty male subjects ( $19-40$ years; $31.1 \pm 4.6$ years) with normal total cholesterol levels $(3.9 \pm 0.6 \mathrm{mmol} / \mathrm{L})$ participated in the study. All subjects completed the ocular surface disease index assessment first, followed by the non-invasive tear break-up time (NITBUT) test. After 10 minutes, the tear meniscus time (TMH) test was performed followed by phenol red thread (PRT) and tear ferning (TF) tests, with a 10-minute gap between the tests.
\end{abstract}

Results: The mean scores $(p<0.05)$ in the NITBUT and TMH tests indicated a dry eye condition in the study group [7.5 (3.3) s and $0.15(0.12) \mathrm{mm}$, respectively] and a normal eye condition in the control group $[15.3(4.1) \mathrm{s}$ and $0.27(0.06)$ $\mathrm{mm}$, respectively]. The average score for the TF grade $(p<0.05)$ showed eye dryness $[2.2(1.8)]$ in the study group and a normal eye condition in the control group [0.5 (1.5)]. The cholesterol level showed a medium correlation with age $(r=0.473$; $p=0.035)$, a strong negative correlation with the PRT score $(r=-0.524 ; p=0.018)$, and a strong correlation with the TF grade $(r=0.530 ; p=0.016)$.

Conclusion: The total cholesterol level significantly influences ocular tear film stability. Both tear quantity and quality decreased in subjects with high total cholesterol levels, which led to meibomian gland dysfunction and disturbances in lipid production and blood and oxygen supply to eye tissues, thereby causing dry eye symptoms.

Key Words: Total blood cholesterol level - Dry eye - Tear film - Tear ferning test - Non-invasive tear breakup time

Correspondence to: Dr. Saud A. Alanazi, E-Mail: saaalanazi@ksu.edu.sa

\section{Introduction}

THE tear film is a moist thin layer that covers the cornea and conjunctiva [1]. The thickness of the tear film varies from around $9 \mathbf{m}$ (after a blink) to approximately $4 \mathrm{~m}$ (mefore the following blink), and its average thickness is $4.8 \pm 0.9$ tear film ensures a smooth, perfect, and regular ocular surface, keeps the conjunctiva lubricated and moist, helps tears flow over the ocular surface through blinking, washes debris away, adjusts the osmotic pressure with the cornea, provides oxygen, nutrition, and blood to the corneal surface, and acts as a barrier against microorganism infections [4].

The structure of the tear film is complex, and is composed mainly of the outer lipid layer, the middle aqueous layer, and the inner mucous layer [5-7]. The outer lipid layer is oily and thin and produced by the meibomian glands [8]. This layer plays a vital role in reducing the tear evaporation rate and prevents over-spilling of tears onto the eyelid [9]. The aqueous layer mainly consists of water and contains dissolved electrolytes, enzymes, and proteins and originates generally from the main lacrimal gland and the accessory glands of Krause and Wolfring [10]. The type and concentration of electrolytes are very important for normal tear osmolarity [11]. The outer mucous layer of the tear film is mainly produced by goblet cells and plays an important role in hydrating the surface of the conjunctiva and cornea [12]. The stability of the tear film is important for a healthy visual system. Tear film instability could result in dysfunction of the conjunctiva and eyelids, a reduction in corneal transparency, and dry eye symptoms, for example [13]. 
Dry eye is a multifactorial disease that leads to dryness, discomfort, eye pain, inflammation, and redness [13,14]. The dry eye condition can occur due to a high tear evaporation rate as a result of meibomian gland dysfunction or due to tear secretion deficiency as a result of lacrimal gland dysfunction [15]. Dry eye questionnaire-based parameters such as the ocular surface disease index (OSDI) are very useful to detect dry eye symptoms [16]. A combination of various diagnostic tests can be used to measure the volume and quality of tears. For example, the tear evaporation rate [17], tear meniscus height (TMH) [18], phenol red thread (PRT) [19], and Schirmer [19] tests can be used to measure the tear volume, while assessments of parameters such as non-invasive tear break-up time (NITBUT) [20], osmolarity [21] and tear ferning (TF) [22] can be used to evaluate tear quality. Early detection of the eye dryness can improve the patients' quality of life.

Cholesterol is essential for cells and is needed for the generation and maintenance of membranes. Cholesterol is a lipid molecule that presents as a free acid that can be esterified in the plasma to produce the ester form [23]. The two major types of cholesterol are categorized as low-density lipoprotein (LDL) and high-density lipoprotein (HDL) [24] . LDL, which is colloquially known as "bad cholesterol," contributes to the buildup of fats in arteries and increases the chances of stroke, cardiac arrest, and other illnesses. In contrast, HDL, which is similarly known as "good cholesterol", acts as an LDL scavenger and transports it back to the liver, where the cholesterol is broken down and excreted from the body. Cholesterol (LDL or HDL) combines with triacylglycerols to produce a lipoprotein core [25]. Cholesterol has a vital impact on the structure and function of cells and is considered to be a precursor for bile acid and steroid hormone synthesis [26,27]. Therefore, cholesterol levels have to be checked regularly to avoid health problems caused by high levels. The aim of the current work was to assess, for the first time, the ocular tear film stability among subjects with high levels of total cholesterol by using various dry eye diagnostic tests. This study is a continuation of previous research on the tear film, which includes studies on tear film stability among smokers [28] and subjects who consumed hot peppermint [29], green tea [30], and vitamin A supplements [31]

\section{Subjects and Methods}

Subjects:

Twenty male subjects aged 19-43 years (32.5 \pm 7.3 years) with a high total cholesterol level (mean \pm standard deviation $=6.2 \pm 0.7 \mathrm{mmol} / \mathrm{L}$ ) participated in the study. In addition, an age-matched control group consisting of twenty male subjects aged 1940 years ( $31.1 \pm 4.6$ years) with a normal total cholesterol level $(3.9 \pm 0.9 \mathrm{mmol} / \mathrm{L})$ was recruited. Subjects with a history of ocular surgery, contact lens wearers, patients with diabetes, smokers, patients with anemia, vitamin A and D deficiencies, or thyroid disorders, and individuals with a high body mass index were excluded from the study. Subjects older than 43 years were excluded since aging is known to be a risk factor for dry eye [32]

The study was conducted at King Khalid Hospital, Riyadh, Saudi Arabia during the period from February to April 2019 and all tests were performed in the right eye of each subject. The measurements were conducted between 8:30am to 3:00pm. Ethical approval was obtained from the College of Applied Medical Science Ethics Committee, King Saud University. The study was conducted in accordance with the Declaration of Helsinki [33] and all participants provided written informed consent. All measurements were carried out by the same examiner under normal conditions. All subjects completed the OSDI questionnaire first, followed by the NITBUT test. After 10 minutes, the TMH test was performed, which was followed by the PRT and TF tests, with a 10-minute gap allowed between tests.

\section{Cholesterol:}

A total blood cholesterol level less than $5.2 \mathrm{mmol}$ /L was considered desirable, levels between 5.2 and $6.2 \mathrm{mmol} / \mathrm{L}$ were considered borderline high, and those above $6.2 \mathrm{~mm} / \mathrm{L}$ were considered high [34].

\section{OSDI:}

The OSDI questionnaire was completed by all participants, and an OSDI value less than 13 is considered to indicate a normal eye [16]

\section{TMH and NITBUT tests:}

Both NITBUT and TMH tests were performed with the OCULUS Keratograph ${ }^{\circledR} 4$ (OCULUS Inc., Wetziar, Germany) on the right eye of each subject by using fluorescein. For the NITBUT test, each subject was asked to refrain from blinking while the tear film was observed. The visibility of the tear film break-up was enhanced by using a yellow barrier filter. The tear break-up time was recorded as the number of seconds that elapsed between the last blink and the appearance of the first dry spot in the tear film. A tear film break-up time of more than $10 \mathrm{~s}$ is considered to indicate a normal eye. The inferior TMH images were cap- 
tured and measured perpendicular to the lid margin at the central point relative to the pupil center by using an integrated ruler (mm). A lower lid TMH $>0.2 \mathrm{~mm}$ was considered to indicate a normal eye.

\section{PRT test:}

The PRT test was performed by using a cotton thread (Zone-Quick, Showa Yakuhin Kako Co, Ltd., Tokyo, Japan) containing a pH indicator. A 3-mm portion of the thread was folded and inserted up to one-third of the distance from the temporal canthus of the lower eyelid of the right eye, with the eye in the primary position. After $15 \mathrm{~s}$, the thread was gently removed and the length of the portion that showed a change in color to red was measured in $\mathrm{mm}$. A red portion more than $10 \mathrm{~mm}$ long was considered to indicate a normal eye [19]

\section{TF test:}

A glass capillary tube (10 L L Labtained from Merck (Schnelldorf, Germany) was used to collect a tear sample (1 1 ) com the lower meniscus of the right eye in each subject. The tear sample was dried at $23^{\circ} \mathrm{C}$ and humidity of less than $40 \%$ for 10min. An Olympus DP72 digital microscope (Tokyo, Japan) at a magnification power of 10x was used to observe and capture the TF image. The TF pattern of each image was graded using the five-point TF grading scale [35].

\section{Statistical analysis:}

The data were analyzed using version 22 of SPSS software (IBM, Armonk, NY, USA). Spearman correlation coefficient $(r)$ values were used to investigate the relationship between the obtained data. The correlation was considered weak when $r=0.10-0.29$, medium when $r=0.30-0.49$, and strong when $r=0.50-1.00$ [3 6]

\section{Results}

Twenty male subjects with a high total cholesterol level comprised the study group, and the agematched control group contained twenty healthy male subjects. The total cholesterol level data showed a normal distribution (KolmogorovSmirnov test; $p>0.05)$; therefore, the mean \pm standard deviation (SD) was used to represent the average. The data for the OSDI, NITBUT, TMH, PRT, and TF values were found to show an abnormal distribution (Kolmogorov-Smirnov test; $p$-0.05) and, therefore, the median (interquartile range) was used to represent these findings. The averages for the total cholesterol level and OSDI, NITBUT, TMH, PRT, and TF values within the study and control groups are shown in Table (1).
Table (1): Averages [mean \pm standard deviation or median (interquartile range)] for the total cholesterol level and OSDI, NITBUT, TMH, PRT, and TF values within the study and control groups.

\begin{tabular}{lll}
\hline Test* & $\begin{array}{c}\text { Study group } \\
(\mathrm{n}=20)\end{array}$ & $\begin{array}{c}\text { Control group } \\
(\mathrm{n}=20)\end{array}$ \\
\hline Cholesterol $(\mathrm{mmol} / \mathrm{L})$ & $6.2 \pm 0.7$ & $3.9 \pm 0.6$ \\
OSDI score & $7.5(4.8)$ & $4.0(3.5)$ \\
NITBUT $(\mathrm{sec})$ & $7.5(3.3)$ & $15.3(4.1)$ \\
TMH $(\mathrm{mm})$ & $0.15(0.12)$ & $0.27(0.06)$ \\
PRT $(\mathrm{mm})$ & $25.0(9.5)$ & $29.5(6.5)$ \\
TF grade & $2.2(1.8)$ & $0.5(1.5)$ \\
\hline
\end{tabular}

$\begin{array}{lll}* & : \text { Statistically significant value at } & p<0.05 . \\ \text { OSDI } & : \text { Ocular surface disease index. } \\ \text { NITBUT : Non-invasive tear break-up } & \\ & \text { time. } & \text { PRT: Phenol red thread. } \\ \text { TMH } & : \text { Tear meniscusheight. } & \text { TF : Tear ferning. }\end{array}$

There were significant (Kolmogorov-Smirnov test; $p<0.05)$ intergroup differences in these values. The mean scores for the NITBUT and TMH tests showed a dry eye condition in the study group [7.5 (3.3) s and $0.15(0.12) \mathrm{mm}$, respectively] and a normal eye condition in the control group [ 15.3 (4.1) s and $0.27(0.06) \mathrm{mm}$, respectively]. Similarly, the average TF grade $(p<0.05)$ indicated eye dryness in the study group [2.2 (1.8)] and a normal eye condition in the control group $[0.5(1.5)]$. The TF grades indicated eye dryness in $65 \%(n=13)$ of the subjects in the study group. The PRT test results in the study and control groups showed an acceptable tear volume [25.0 (9.5) and 29.5 (6.5) $\mathrm{mm}$, respectively). However, the tear volume was significantly $(p<0.05)$ lower in the study group than that in the control group. The average OSDI value in the study group indicated no dry eye symptoms [7.5 (4.8)]. However, the OSDI average score within the control group was significantly $(p<0.05)$ lower [4.0 (3.5)]. Representative TF images obtained from a number of subjects within the study group are shown in Fig. (1). The side-by-side boxplots for the OSDI, NITBUT, TMH, PRT, and TF scores the within study and control groups are shown in Figs. (2-6), respectively.

The correlations (Mann-Whitney test; Pearson correlation coefficient, r) among age, total cholesterol, OSDI values, and the values obtained from the NITBUT, TMH, PRT, and TF tests in the study group are recorded in Table (2). The total cholesterol level showed a medium correlation with age ( $r=0.473 ; p=0.035)$, a strong negative correlation with the PRT results ( $r=-0.524 ; p=0.018$ ), and a strong correlation with the TF grades ( $r=0.530$; $p=0.016)$. The TMH values showed a medium negative correlation with age $(r=-0.458 ; p=0.043)$, a strong negative correlation ( $r=-0.521 ; p=0.018$ ) with the OSDI values, and strong correlations with both the NITBUT ( $r=0.518 ; p=0.019)$, and PRT measurements ( $r=0620 ; p=0.004)$. 
Table (2): The correlations among age, total cholesterol level, and OSDI, NITBUT, TMH, PRT, and TF values within the study group $(\mathrm{n}=20)$.

\begin{tabular}{|c|c|c|c|c|c|c|c|}
\hline Correlation & Age & Cholesterol & OSDI & NITBUT & TMH & PRT & $\mathrm{TF}$ \\
\hline \multicolumn{8}{|l|}{ Age: } \\
\hline$r$ & 1 & $0.473^{*}$ & 0.224 & -0.135 & $-0.458 *$ & -0.342 & 0.281 \\
\hline$p$ & - & 0.035 & 0.342 & 0.570 & 0.043 & 0.140 & 0.231 \\
\hline \multicolumn{8}{|l|}{ Cholesterol: } \\
\hline$r$ & $0.473^{*}$ & 1 & 0.042 & -0.336 & -0.385 & $-0.524 *$ & $0.530 *$ \\
\hline$p$ & 0.035 & - & 0.862 & 0.148 & 0.093 & 0.018 & 0.016 \\
\hline \multicolumn{8}{|l|}{ OSDI: } \\
\hline$r$ & 0.224 & 0.042 & 1 & -0.401 & $-0.521 *$ & -0.297 & -0.122 \\
\hline$p$ & 0.342 & 0.862 & - & 0.080 & 0.018 & 0.204 & 0.610 \\
\hline \multicolumn{8}{|l|}{ NITB UT: } \\
\hline$r$ & -0.135 & -0.336 & -0.401 & 1 & $0.518^{*}$ & $0.659 * *$ & -0.219 \\
\hline$p$ & 0.570 & 0.148 & 0.080 & - & 0.019 & 0.002 & 0.353 \\
\hline \multicolumn{8}{|l|}{ TMH: } \\
\hline$r$ & $-0.458 *$ & -0.385 & $-0.521 *$ & $0.518 *$ & 1 & $0.620 * *$ & -0.061 \\
\hline$p$ & 0.043 & 0.093 & 0.018 & 0.019 & - & 0.004 & 0.798 \\
\hline \multicolumn{8}{|l|}{ PRT: } \\
\hline$r$ & -0.342 & $-0.524 *$ & -0.297 & $0.659 * *$ & $0.620 * *$ & 1 & -0.149 \\
\hline$p$ & 0.140 & 0.018 & 0.204 & 0.002 & 0.004 & - & 0.531 \\
\hline \multicolumn{8}{|l|}{$T F:$} \\
\hline$r$ & 0.281 & $0.530^{*}$ & -0.122 & -0.219 & -0.061 & -0.149 & 1 \\
\hline$p$ & 0.231 & 0.016 & 0.610 & 0353 & 0.798 & 0.531 & - \\
\hline
\end{tabular}

* The correlation is significant at the 0.05 level (2-tailed). **The correlation is significant at the 0.01 level (2-tailed).

OSDI : Ocular surface disease index.

TMH: Tear meniscus height.

PRT : Phenol red thread.

NITBUT: Non-invasive tear break-up time.

TF : Tear ferning.
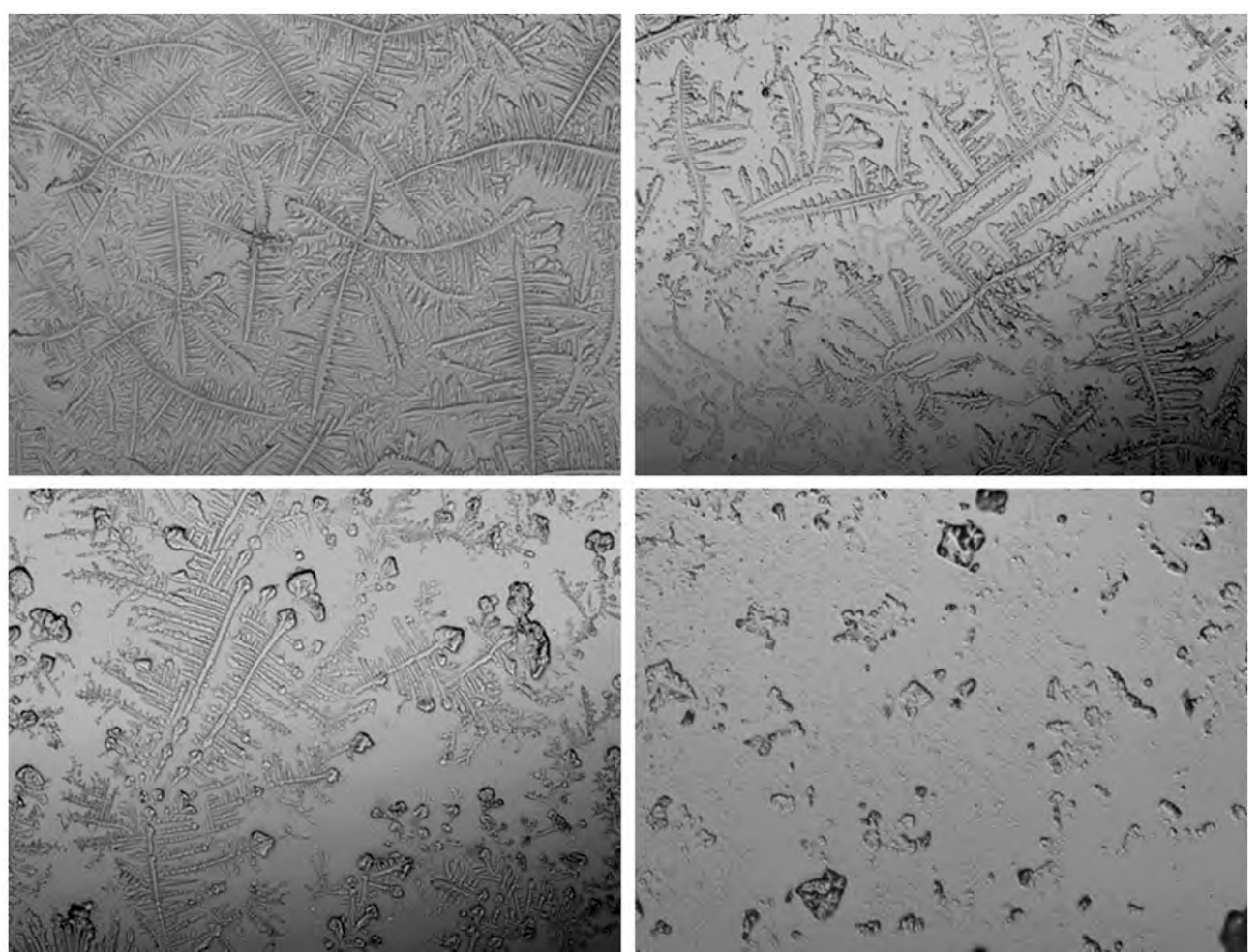

Fig. (1): Representative TF images from some subjects in the study group. 


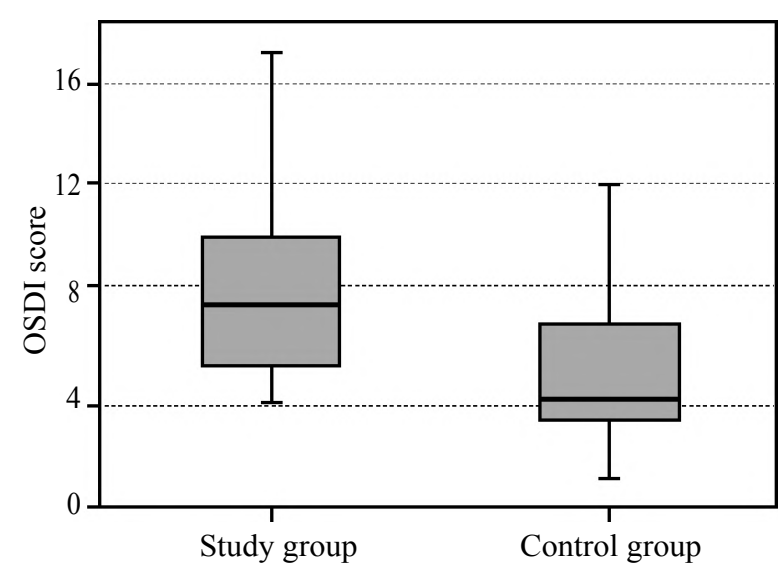

Fig. (2): Side-by-side boxplots for the OSDI values $(p<0.05)$.

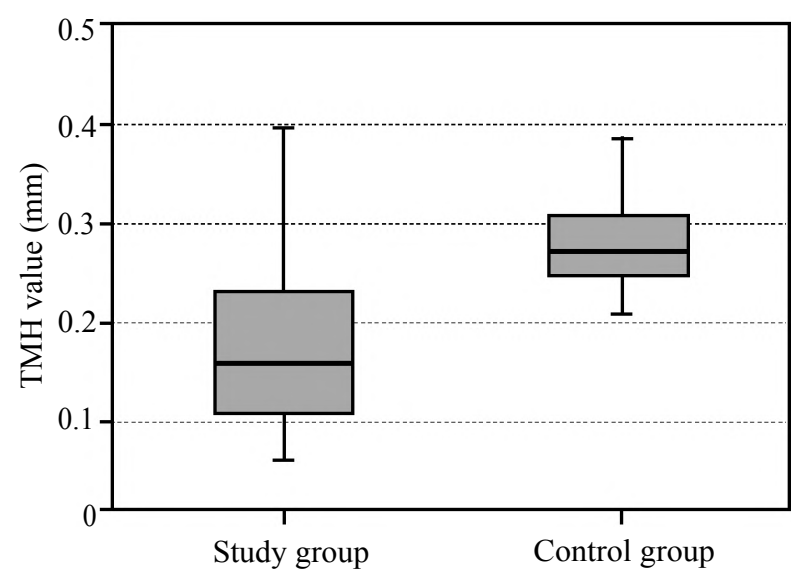

Fig. (4): Side-by-side boxplots for the TMH values $(p<0.05)$.

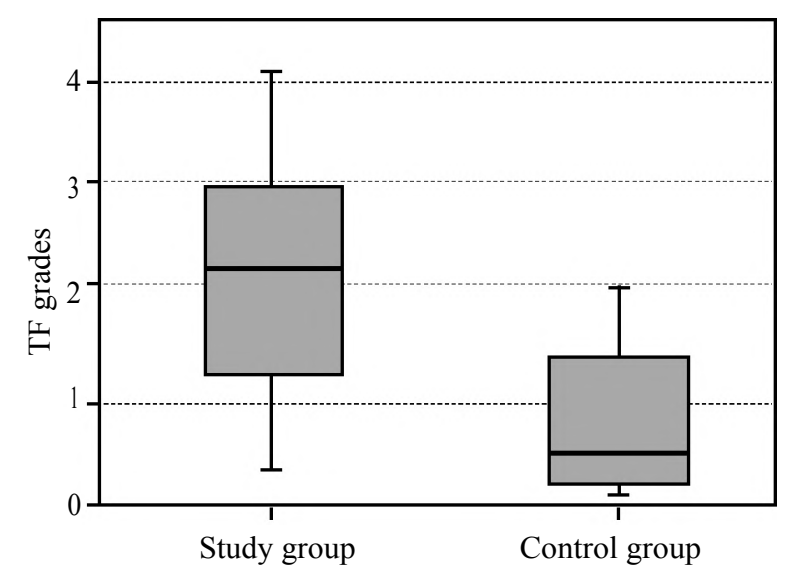

Fig. (6): Side-by-side boxplots for the TF grades $(p<0.05)$.

\section{Discussion}

Dry eye disorder causes various ocular discomfort symptoms. Disruption or dysfunction of the meibomian gland can increase the stress on the ocular surface and alter lipid secretion, leading to symptoms of dryness [37]. Cholesterol plays an important role in the properties and regulation

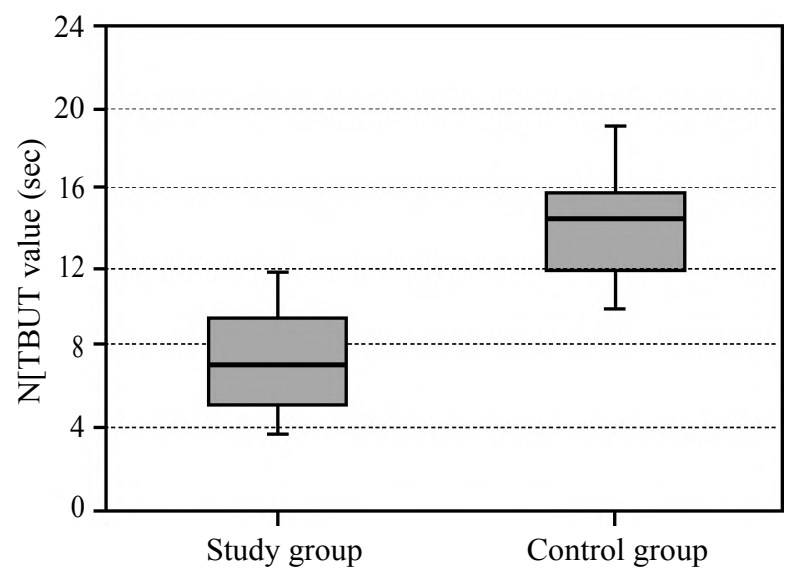

Fig. (3): Side-by-side boxplots for the NITBUT scores $(p<0.05)$.

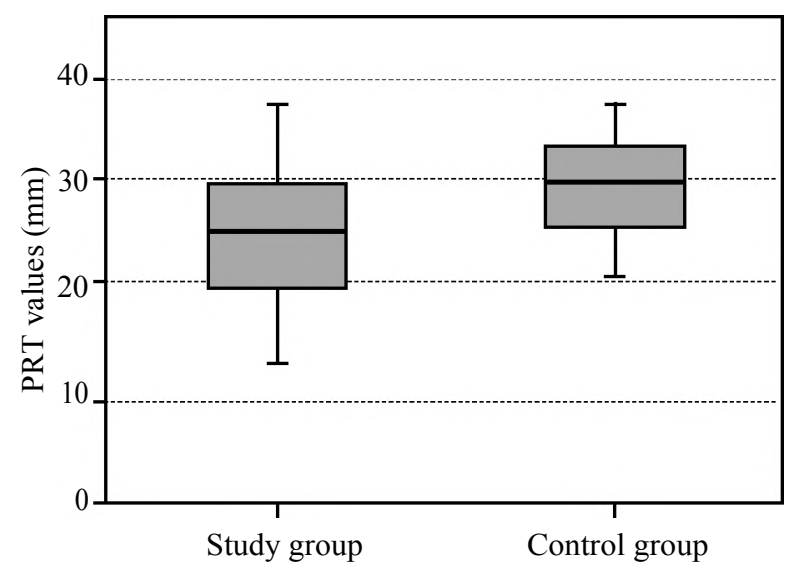

Fig. (5): Side-by-side boxplots for the PRT values $(p<0.05)$.

of phospholipid membranes [38]. The current study assessed the volume and quality of tears in subjects with high levels of total cholesterol. In addition, the OSDI was used to assess the discomfort associated with dry eye. The results indicated a link between the total cholesterol level and eye dryness, with both the quality and quantity of tears being lower in the study group in comparison with those in the control group. The OSDI and the values from the other dry eye diagnostic tests showed significant (Kolmogorov-Smirnov test; $p<0.05$ ) differences between the study and control groups.

A dry eye questionnaire survey $(n=5627)$ conducted in South Korea between 2010 and 2011 suggested a correlation between high cholesterol levels and dry eye symptoms [39]. In that survey, women with higher cholesterol levels were found to be 1.8 times more likely to have dry eye symptoms in comparison with other subjects with lower levels of cholesterol [39]. Women aged between 40 and 50 years may show disturbances in meibomian gland secretion due to the changes in sex hormone 
levels [40]. Thus, postmenopausal and menopausal women can experience dry eye symptoms as a result of a shortage in tear secretion [41]. Another study conducted on dry eye subjects $(n=60)$ showed a significant $(p<0.001)$ association between the total cholesterol level and dry eye symptoms, particularly in women [42]. The authors of that study suggested that changes in cholesterol levels alter the lipid content of the tear film, leading to dry eye symptoms [42]. In addition, Taiwanese dry eye subjects $(n=12007)$ showed a higher prevalence of hyperlipidemia than non-dry eye subjects [43] However, one study showed that serum total cholesterol level was not significantly associated with the incidence of dry eye symptoms [44].

Inadequate lipid production due to dysfunction of the meibomian gland can preclude proper lubrication of the ocular surface, leading to dry eye symptoms [42]. Indeed, strong associations ( $p<$ 0.001 ) have been reported between meibomian gland dysfunction and the level of cholesterol, age, and sex [45]. The reasons for the meibomian gland dysfunction are not fully understood, but it could be caused by obstruction of the gland or a change in its composition [46]. Cholesterol esters were found in the glands of patients diagnosed with meibomian gland dysfunction [47]. In addition, the secretions of dysfunctional meibomian glands were found to be thick, with an altered viscosity $[48,49]$. An association was also found between high serum cholesterol levels and primary open-angle glaucoma in old adults (e40 years) [50]

High levels of cholesterol can harm the retina, vitreous, lens, and the optical nerve. The buildup of cholesterol on the walls of eye blood vessels leads to thick plaque formation, thereby reducing the rate of blood flow. The cholesterol buildup can also lead to serious illnesses, among which eye dryness is one of the least severe conditions. Nevertheless, dry eye symptoms should be diagnosed and treated as early as possible to avoid the resultant serious complications [51]

\section{Limitations:}

The study had some limitations, such as the small, all-male patient population and the fact that subjects were recruited from a single location in Saudi Arabia. In addition, the subjects may have been exposed to high ambient temperature and humidity before taking part in the study, which could have a confounding effect on the findings. Therefore, future studies should aim to involve larger samples that represent different geographical locations and genders.

\section{Conclusion:}

Total cholesterol level has a significant effect on the ocular tear film stability. It appears that both tear quantity and quality decreased in subjects with high total cholesterol levels. A high cholesterol level leads to meibomian gland dysfunction and results in disturbances in lipid production and the supply of blood and oxygen to eye tissues, causing dry eye symptoms.

\section{Funding:}

This work was financially supported by the Deanship of Scientific Research, King Saud University through the Vice Deanship of Scientific Research Chairs.

\section{Competing interests:}

The author reports no conflicts of interest in this work.

\section{References}

1- CRAIG J.: Structure and function of the preocular tear film. In The Tear Film: Structure, Function and Clinical Examination. 1 st ed. Butterworth-Heinemann/BCLA: UK, pp. 18-50, 2002.

2- HOLLY F.J.: Tear film physiology and contact lens wear: I. Pertinent aspects of tear film physiology. Am. J. Optom. Physiol. Opt., 58 (4): 324-330, 1981.

3- WERKMEISTER R.M., ALEX A., KAYA S., UNTERHUBER A., HOFER B., RIEDL J., BRONHAGL M., VIETAUER M., SCHMIDL D., SCHMOLL T., GARHÖFER G., DREXLER W., LEITGEB R.A., GROESCHL M. and SCHMETTERER L.: Measurement of tear film thickness using ultrahigh-resolution optical coherence tomography. Invest. Ophthalmol. Vis. Sci., 54 (8): 55785583, 2013.

4- GEORGIEV G.A., EFTIMOV P. and YOKOI N.: Structure-function relationship of tear film lipid layer: A contemporary perspective. Exp. Eye Res., 163: 17-28, 2017.

5- CONRADY C.D., JOOS Z.P. and PATEL B.C.: Review: The lacrimal gland and its role in dry eye. J. Ophthalmol., 7542929, 2016.

6- GOVINDARAJAN B. and GIPSON I.K.: Membranetethered mucins have multiple functions on the ocular surface. Exp. Eye Res., 90 (6): 655-663, 2010.

7- MONTÉS-MICÓ R., CERVIÑO A., FERRER-BLASCO T., GARCÍA-LÁZARO S. and MADRID-COSTA D.: The tear film and the optical quality of the eye. Ocul. Surf., 8 (4): 185-192, 2010.

8- TSAI P.S., EVANS J.E., GREEN K.M., SULLIVAN R.M., SCHAUMBERG D.A., RICHARDS S.M., DANA M.R. and SULLIVAN D.A.: Proteomic analysis of human meibomian gland secretions. Br. J. Ophthalmol., 90 (3): 372-377, 2006.

9- GEORGIEV G.A., EFTIMOV P. and YOKOI N.: Structure-function relationship of tear film lipid layer: a contemporary perspective. Exp. Eye Res., 163: 17-28, 2017. 
10- DARTT D.A. and WILLCOX M.D.P.: Complexity of the tear film: Importance in homeostasis and dysfunction during disease. Exp. Eye Res., 117: 1-3, 2013.

11- STAHL V., WILLCOX M. and STAPLETON F.: Osmolality and tear film dynamics. Clin. Exp. Optom., 95 (1): 3-11, 2012.

12-HODGES R.R. and DARTT D.A.: Tear film mucins: Front line defenders of the ocular surface; comparison with airway and gastrointestinal tract mucins. Exp. Eye Res. 117: 62-78, 2013

13- GAYTON J.L. : Etiology, prevalence, and treatment of dry eye disease. Clin. Ophthalmol., 3: 405-412, 2009.

14- CRAIG J.P., NICHOLS K.K., AKPEK E.K., CAFFERY B., DUA H.S., JOO C.K., LIU Z., NELSON J.D., NICHOLS J.J., TSUBOTA K. and STAPLETON F.: TFOS DEWS II Definition and Classification Report Ocul. Surf., 15 (3): 276-283, 2017

15- KNOP E., KNOP N., MILLAR T., OBATA H. and SULLIVAN D.A.: The international workshop on meibomian gland dysfunction: Report of the subcommittee on anatomy, physiology, and pathophysiology of the meibomian gland. Invest. Ophthalmol., Vis. Sci., 52 (4): 193 8-1978, 2011.

16- SCHIFFMAN R.M., CHRISTIANSON M.D., JACOBSEN G., HIRSCH J.D. and REIS B.L.: Reliability and validity of the Ocular Surface Disease index. Arch. Ophthalmol., 118 (5): 615-621, 2000.

17- ABUSHARAHA A., ALTURKI A.A., ALANAZI S.A., FAGEHI R., AL-JOHANI N., EL-HITI G.A. and MASMALI A.M.: An assessment of the tear evaporation rate in thyroid gland patients. Clin. Ophthalmol., 13: 131-135, 2019.

18- IBRAHIM O.M., DOGRU M., TAKANO Y., SATAKE Y., WAKAMATSU T.H., FUKAGAWA K., TSUBOTA K. and FUJISHIMA H.: Application of Visante optical coherence tomography tear meniscus height measurement in the diagnosis of dry eye disease. Ophthalmology, 117 (10): 1923-1929, 2010.

19- MASMALI A., ALQAHTANI T.A., ALHARBI A. and EL-HITI G.A.: Comparative study of repeatability of phenol red thread test versus Schirmer's test in normal adults in Saudi Arabia. Eye Contact Lens, 40 (3): 127 131,2014

20- MZUMARA T. and AFONNE J.: Assessing the relationship between non-invasive tear break-up time and maximum blink interval values among young adults at Mzuzu University. Clin. Optom., 10: 87-91, 2018.

21- MASMALI A., ALRABIAH S., ALHARBI A., EL-HITI G.A. and ALMUBRAD T.: Investigation of tear osmolarity using the TearLabTM osmolarity system in normal adults in Saudi Arabia. Eye Contact Lens, 40 (2): 74-78, 2014.

22- MASMALI A.M., AL-QHTANI S., AL-GASHAM T.M., EL-HITI G.A., PURSLOW C. and MURPHY P.J.: Application of a new grading scale for tear ferning in non-dry eye and dry eye subjects. Cont. Lens Anterior Eye, 38 (1): 39-43, 2015

23- MATTHIAS ORTH M. and BELLOSTA S.: Cholesterol: its regulation and role in central nervous system disorders. Cholesterol., 292598, 2012.
24- CHUNG S. and PARKS J.S.: Dietary cholesterol effects on adipose tissue inflammation. Curr. Opin. Lipidol., 27 (1): 19-25, 2016.

25- STEIN O. and STEIN Y.: Lipid transfer proteins (LTP) and atherosclerosis. Atherosclerosis, 178 (2): 217-23 0, 2005 .

26- LEVITAN I., SINGH D.K. and ROSENHOUSEDANTSKER A.: Cholesterol binding to ion channels. Front. Physiol., 5: 65, 2014.

27- MCLEAN K.J., HANS M. and MUNRO A.W.: Cholesterol, an essential molecule: Diverse roles involving cytochrome P450 enzymes. Biochem. Soc. Trans., 40 (3): 587-593, 2012.

28- MASMALI A.M., AL-SHEHRI A., ALANAZI S.A. ABUSHARAHA A., FAGEHI R. and EL-HITI G.A.: Assessment of tear film quality among smokers using tear ferning patterns. J. Ophthalmol., 8154315, 2016.

29- MASMALI A.M., ALANAZI S.A., ALMAGREN B. and EL-HITI G.A.: Assessment of the tear film in normal eye subjects after consumption of a single dose of hot peppermint drink. Clin. Optom., 11: 3 9-45, 2019.

30- MASMALI A.M., ALOTAIBI A.G., ALANAZI S.A., FAGEHI R., ABUSHARAHA A. and EL-HITI G.A.: The acute effect of a single dose of green tea on the quality and quantity of tears in normal eye subjects. Clin. Ophthalmol., 13: 605-610, 2019.

31- ALANAZI S.A., EL-HITI G.A., AL-BALOUD A.A., ALFARHAN M.I., AL-SHAHRANI A., ALBAKRI A.A., ALQAHTANI S. and MASMALI A.M.: Effects of shortterm oral vitamin A supplementation on the ocular tear film in patients with dry eye. Clin, Ophthalmol., 13: 599604, 2019.

32- MOSS S.E., KLEIN R. and KLEIN B.E. : Long-term incidence of dry eye in an older population. Optom. Vis. Sci., 85 (8): 668-674, 2008

33- World Medical Association Declaration of Helsinki: ethical principles for medical research involving human subjects. JAMA, 310 (20): 2191-2194, 2013.

34- Mayo Clinic. Patients care \& Health Information. Cholesterol test. https://www.mavoclinic.org/tests-procedures/ cholesterol-test/about/pac-20384601 [Accessed on 12 July 2019].

35- MASMALI A.M., MURPHY P.J. and PURSLOW C. Development of a new grading scale for tear ferning. Cont. Lens Anterior Eye, 37 (3): 178-184, 2014.

36- COHEN J.W.: Statistical power analysis for the behavioral sciences. 2nd ed. Hillsdale (NJ): Lawrence Erlbaum Associates, 1988

37- NICHOLS K.K.: The International Workshop on Meibomian Gland Dysfunction: introduction. Invest. Ophthalmol. Vis. Sci., 52 (4): 1917-1921, 2011.

38- de MEYER F. and SMIT B.: Effect of cholesterol on the structure of a phospholipid bilayer. Proc. Natl. Acad. Sci USA, 106 (10): 3654-3658, 2009.

39- CHUN Y.H., KIM H.R., HAN K., PARK Y.G., SONG H.J. and NA K.S.: Total cholesterol and lipoprotein composition are associated with dry eye disease in Korean women. Lipids Health Dis., 12: 84, 2013. 
40- YAZDANI C., MCLAUGHLIN T., SMEEDING J.E. and WALT J.: Prevalence of treated dry eye disease in a managed care population. Clin. Ther., 23 (10): 1672-1682, 2001.

41- LAMBERT D.W., FOSTER C.S. and PERRY H.D.: Schirmer test after topical anesthesia and the tear meniscus height in normal eyes. Arch. Ophthalmol., 97 (6): 1082 $1085,1979$.

42- RATHNAKUMAR K., RAMACHANDRAN K., BABA D., RAMESH V., ANEBARACY V., VIDHYA R., VINOTHKUMAR R., POOVITHA R. and GEETHA R.: Prevalence of dry eye disease and its association with dyslipidemia. J. Basic Clin. Physiol. Pharmacol., 29 (2): 195-199, 2018.

43- WANG T.J., WANG I.J., HU C.C. and LIN H.C.: Comorbidities of dry eye disease: A nationwide population-based study. Acta Ophthalmol., 90 (7): 663-668, 2012.

44- MOSS S.E., KLEIN R. and KLEIN B.E.: Prevalence of and risk factors for dry eye syndrome. Arch. Ophthalmol., 118 (9): 1264-1268, 2000.

45- GULIANI B.P., BHALLA A. and NAIK M.P.: Association of the severity of meibomian gland dysfunction with dyslipidemia in Indian population. Indian J. Ophthalmol., 66 (10): 1411-1416, 2018.
46- KNOP E., KNOP N., MILLAR T., OBATA H. and SULLIVAN D.A.: The International Workshop on Meibomian Gland Dysfunction: Report of the subcommittee on anatomy, physiology, and pathophysiology of the meibomian gland. Invest. Ophthalmol. Vis. Sci., 52 (4): 1938-1978, 2011.

47- SHINE W.E. and MCCULLEY J.P.: Role of wax ester fatty alcohols in chronic blepharitis. Invest. Ophthalmol. Vis. Sci., 34 (13): 3515-3521, 1993.

48- SHINE W.E. and MCCULLEY J.P.: Polar lipids in human meibomian gland secretions. Curr. Eye Res., 26 (2): 8994, 2003.

49- BUTOVICH L.A.: Lipidomics of human meibomian gland secretions: Chemistry, biophysics, and physiological role of meibomian lipids. Prog. Lipid Res., 50 (3): 278-301, 2011.

50- KANG J.H., BOUMENNA T., STEIN J.D., KHAWAJA A., ROSNER B.A., WIGGS J.L. and PASQUALE L.R.: Association of statin use and high serum cholesterol levels with risk of primary open-angle glaucoma. JAMA Ophthalmol., [Epub ahead of print], 2019.

51- MARTÍN M.G., PFRIEGER F. and DOTTI C.G.: Cholesterol in brain disease: Sometimes determinant and frequently implicated. EMBO Rep., 15 (10): 1036-1052, 2014.

\title{
تقييم أستقرار دموع العين مع المستويات المرتفعة لكوليسترول الدم
}

\author{
الهفدمة: من المعروف أن مستويات الكوليسترول المرتفعة تسبب مضاعفات متعددة، ويمكن إستخدام الإرتباطات بين جفاف العين ومستويات \\ الكوليسترول المرتفعة كمؤشر على الحاجة إلى علاج عاجل لمنع المضاعفات الشديدة. \\ الهدف من الدراسة: تهدف هذه الدراسة إلى تقييم ثبات نوعية دموع العين فى الأشخاص الذين يعانون من ارتفاع مستويات الكوليسترل \\ الكلى عند طريق إستخدام إختبارات تشخيص العين الجافة المختلفة.

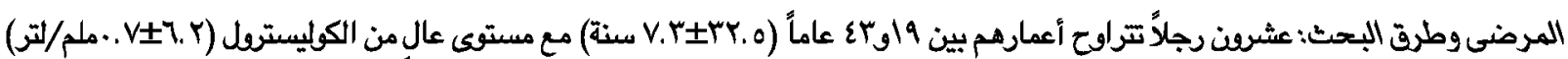

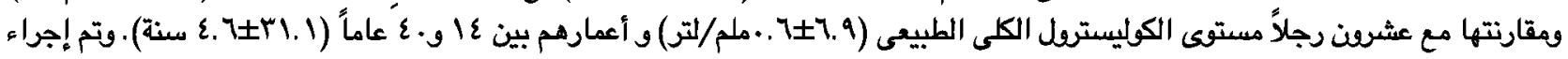 \\ الفحص بقياسات مختلة يفصل بين كل قياس • ادقائق. \\ قد أظهرت نتائج الدراسة: ظههد جفاف العيون فى مرضى الكوليسترول مقارنة مع عينة الرجال الذين لديهم مستوى كوليسترول طبيعى.

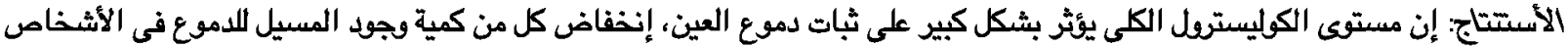

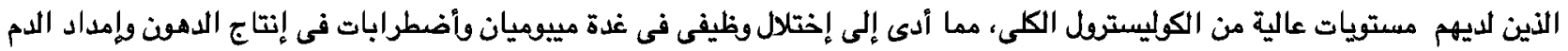 \\ والأكسجين لأنسجة العين، وبالتالى تسبب أعراض جفاف العين العين.
}

